\title{
DISEASES OF THE HEART IN THE WORKS OF HIPPOCRATES
}

\author{
BY \\ ARNOLD M. KATZ* AND PHYLLIS B. KATZ \\ From the Institute of Cardiology \\ Received July 4, 1961
}

\begin{abstract}
"He who would make accurate forecasts as to those who will recover, and those who will die, and whether the disease will last a greater or less number of days, must understand all the symptoms thoroughly and be able to appreciate them, estimating their powers when they are compared with one another, as I have set forth."
\end{abstract}

Hippocrates, Prognostic XXV (Jones, 1923-31)

The works attributed to Hippocrates contain some of the finest clinical descriptions recorded in antiquity. Recent emphasis on the occurrence of heart disease amongst various populations has led to the re-examination of these writings for reference to cardiovascular disease, apart from the purely historical interest. Descriptions of heart failure, rheumatic fever, cardiac pain, AdamsStokes syndrome, and Cheyne-Stokes respiration, as well as the techniques of abdominal and thoracic paracentesis and acupuncture, indicate that Greek physicians of the fifth century B.C. had experience with many disorders of the heart.

There is no doubt that a great physician named Hippocrates lived in classical Greece (Edelstein, 1939; Katz, 1959); however, the seventy-odd books attributed to him (Littré, 1839-1861) represent the work of many physicians and philosophers who lived and worked over a period of several centuries. Commentators from Galen onwards have rejected most of these books as being spurious and it is impossible to state with certainty that any of them were written by Hippocrates himself(Edelstein, 1939). On the other hand, it is very likely that some were written during Hippocrates' lifetime (460-c. 370 B.C.). It has been suggested that the Hippocratic collection might be the library of Hippocrates' school of medicine on the island of Cos (Jones, 1923-31). Several of the books are distinguished for their carefully recorded histories and detailed observations of the diseases then prevalent. These clinical books have been ascribed by some modern commentators to Hippocrates and the present paper follows the classification of Jones (1923-31) who regarded the books Prognostic, Regimen in Acute Diseases, and Epidemics $I$ and $I I I$ as likely to be genuine works of Hippocrates while Aphorisms, Airs, Waters, Places, Fractures, and Wounds in the Head are closely related to Hippocratic thought, if not genuine. Another aphoristic book that will be referred to is Coan Prognostics: thlis was probably written at the medical school of Cos during the early part of Hippocrates' lifetime and may represent the work of his teachers. The books Diseases II and Internal Affections were probably written at the medical school of Cnidus, on the mainland of Asia Minor, less than fifty miles from Cos, possibly during the lifetime of Hippocrates (Littré, 1839-1861; Jones, 1923-1931). These books provide most of the material for the present paper: where other books of the Hippocratic collection are quoted, a comment as to their probable origin will be made.

* Moseley Travelling Fellow of Harvard University. Present address: Cardiovascular Research Laboratory, U.C.L.A. Medical Center, Los Angeles 24. California. 
The diagnosis of specific diseases from descriptions in the Hippocratic writings is, of necessity, imprecise. Errors in the texts are numerous since all of the works have come through several transcriptions. The oldest manuscript is from the 10th century A.D. Interpolations that were added in antiquity have been included in many texts and in some places may have become indistinguishable from the original work. The limited number of facts given renders many of the case histories and clinical descriptions difficult to interpret. Furthermore, the information given by the ancient physicians is often coloured by preconceived ideas about ætiology and pathogenesis of disease. This lack of objectivity is particularly noticeable in certain of the non-Hippocratic books where the facts of the condition being described are all but obscured by statements supporting various a priori systems of physiology. Accurate translation of medical terms from the ancient Greek has been left to three authorities on the Hippocratic writings, Littré (1839-1861), Jones (1923-1931), and Adams (1849). In a few cases, ambiguities have been resolved through consultation of Greek dictionaries, and interpretation of the clinical syndrome under consideration.

Clinical medicine in ancient Greece was not supported by an understanding of the structure and function of the circulatory system. The first careful anatomical studies were carried out in Alexandria after Hippocrates' death, but in spite of some remarkably accurate work in these sciences, medicine remained dominated by philosophic doctrines. Many of the non-Hippocratic books in the collection were concerned with physiology but they do not exhibit a uniform body of anatomical or physiological knowledge. The books of Hippocrates himself are almost devoid of physiological speculation; indeed, their greatness lies in the objective descriptions presented without attempts to explain pathogenesis.

Location of the Intellect. One important question being debated at the time of Hippocrates was the location of the intellect. Some writers placed consciousness in the heart while others said it rested in the brain. The author of a book that was closely related to Hippocratic thought supported the latter hypothesis: "the parts by the heart called ears [ $\hat{\omega} \tau \alpha$, i.e. the auricles] contribute nothing towards hearing. Some people say that it is the heart that is the organ with which we think and that it feels pain and anxiety. But it is not so ... it is the brain which is the [interpreter of consciousness]." The Sacred Disease XX (Jones, 1923-1931).

On the other hand, a reference to pyogenic pericarditis complicating pneumonia appears to support the view that the heart is the seat of awareness by attributing unconsciousness to cardiac involvement: "In cases where the whole lung is inflamed, together with the heart . . . the patient is wholly paralysed and lies cold and insensible. He dies on the second or third day." Coan Prognostics 395 (Littré, 1839-1861; Chadwick and Mann, 1950).

The surgical book, Wounds in the Head, deals extensively with the effects of trauma and the contralateral paralysis resulting from head injury was clearly described: "if the patient has the lesion on the left side of the head, spasm seizes the right side of the body, if he has the lesion on the right side of the head, spasm seizes the left side of the body. Some also become apoplectic and die. ...." Wounds in the Head XIX (Withington, 1927). From this, and similar references in The Sacred Disease, it is unlikely that Hippocrates considered consciousness to have resided in the heart.

Anatomy and Physiology of the Heart and Blood Vessels. One of the finest ancient anatomical treatises is The Heart, a book written about the time of Hippocrates' death by an unknown author (Hurlbutt, 1939). The position of the heart and the anatomical relations of the ventricles in the body were accurately described in this book of the Hippocratic collection. The independent contraction of the atria was noted: "one might observe the heart tossing about as a whole, but the ears independently inflating and collapsing" The Heart VIII (Hurlbutt, 1939). Perhaps the most remarkable observation made by this fine anatomist was the following description of the cardiac valves: "membranes and other muscles resembling spiderwebs spread out, gird everywhere the outlets and send fibers into the solid parts of the heart. . . . There is a pair of [veins] at the entrance to which there have been constructed three membranes for each, rounded at the extremity at least, to the extent of a half-circle, and when they come together it is marvellous that they close the outlets, the end of the veins. ... If someone ... removes the heart of a dead man and takes up one of these membranes 


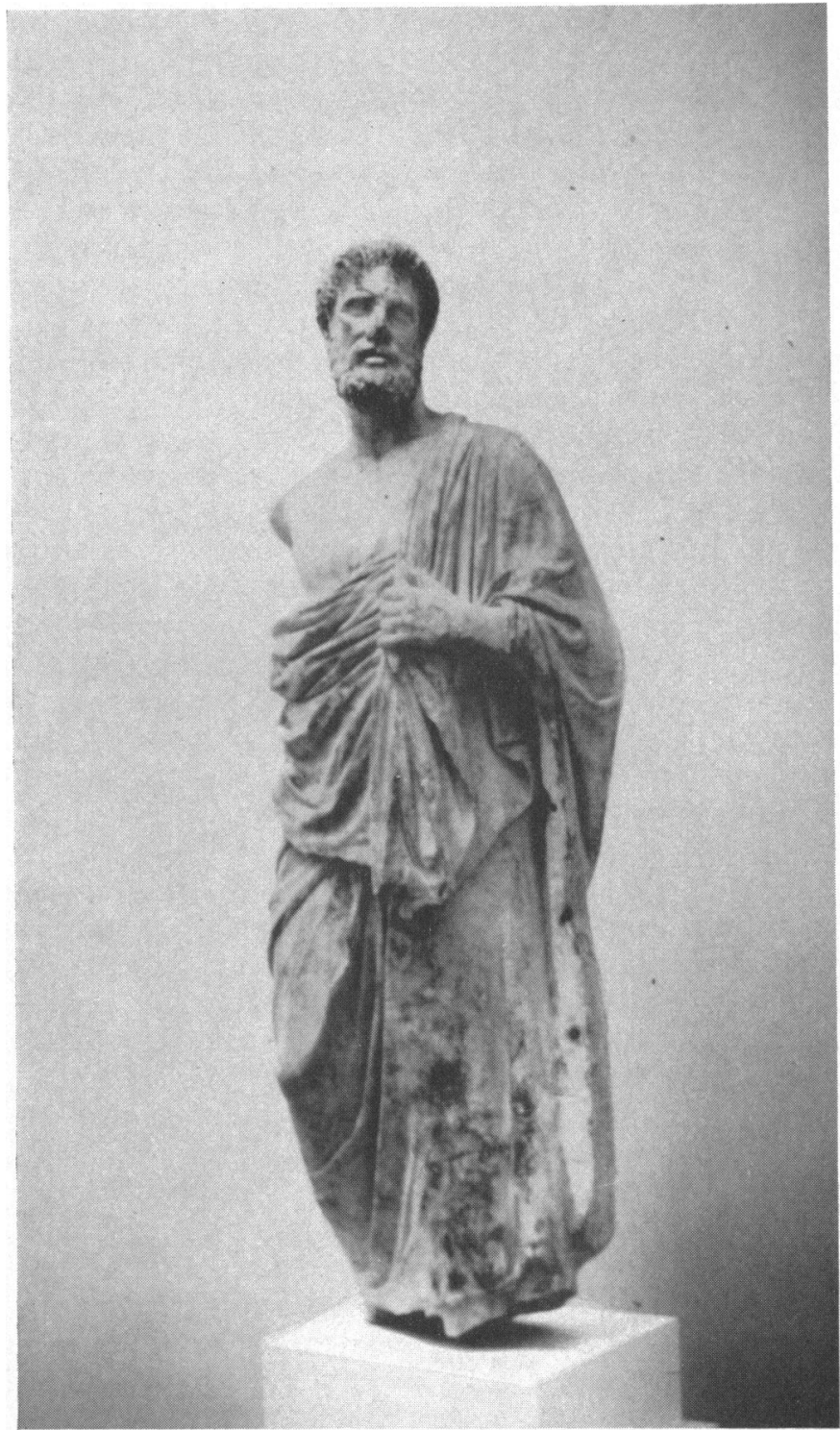

This 4th century в.c. Greek statute, found in 1929 on Cos, is alleged to be a likeness of the island's famous physician. The work resembles that of Praxiteles and may have been executed during Hippocrates' lifetime. There is, however, no conclusive evidence to support the view that this, or indeed any work, provides a true portrait of Hippocrates.

Photograph by the author. Archeological Museum of Cos. 
and bends another up against it, water will not go through into the heart, nor even the breath when forced in." The Heart X (Hurlbutt, 1939). The arteries were not clearly distinguished from the veins by Greek anatomists until the third century B.C. and the same terms are used for both in the Hippocratic collection. For example, the temporal artery was described as a "large and thick vein $[\phi \lambda \epsilon \psi]$ that extends through the temporal region." Wounds in the Head II (Withington, 1927). The same root word described the vein in the antecubital fossa: "the bend of the elbow, about the bifurcation of the vein [ $\phi \lambda \epsilon \beta o s]$ which passes upwards along the [biceps] muscle." Fractures XLIV (Withington, 1927). Necrosis following tight bandaging was discussed in relation to splinting of fractures, and a symptom of arterial occlusion was described: "Should minor veins be so compressed that the breath cannot pass through the vein, a numbness immediately seizes [that part of the body]," The Sacred Disease VII (Jones, 1923-1931). One additional statement may be quoted from a book added to the Hippocratic collection by a later Greek writer. This indicates some understanding of vasomotor tone: "The changing colours [of the skin] are produced by the heart by constricting or relaxing the veins; when it relaxes them, the complexion becomes animated, of good colour and translucent; when it constricts them, pale and livid." The Nature of Bones XIX (Littré, 1839-1861). The preceding example must not be considered representative of the understanding of anatomy and physiology in the Hippocratic collection. Most references to these subjects are speculative and the circulation of the blood was unknown.

Physical Signs. Hippocrates' clinical observations were unsurpassed in antiquity and his moderation in reaching conclusions remains an example even today. On the other hand, he certainly overlooked many points in the clinical history, and the art of physical examination was not well developed. Certain signs were carefully described while others were entirely overlooked. As indicated previously, it would have been impossible to organize the clinical history and examination in terms of pathological physiology. Consequently, each element of the clinical picture was independently considered and signs and symptoms were grouped together as they appeared in individual cases.

Hippocrates was a strong advocate of the importance of physical contact between the physician and his patients. Wounds were carefully probed, various parts of the body palpated, and sputum, urine, fæces and other bodily secretions examined in detail. Physical examination of the chest and auscultation are mentioned in the Hippocratic collection. The succussion splash was noted in empyema: "Those who, when shaken by the shoulder make a lot of noise. . ." Coan Prognostics 424 (Littré, 1839-1861; Chadwick and Mann, 1950) and this sign was utilized to locate the side of pleural effusions. Succussion was carried out as follows: "One seats [the patient] on an immobile stool; an assistant holds his arms, and you, shaking him by the shoulders, listen to which side the noise is heard." Diseases II XLVII (Littré, 1839-1861). There are also references to the pleural friction rub: "a noise like two leather straps being rubbed together"; and to râles: "when the ear is held to the chest, and one listens for some time, it may be heard to seethe inside like the boiling of vinegar" (Diseases II LIX and LXI (Littré, 1839-1861)). No mention was made of heart sounds; however it must not be assumed that Hippocrates was unaware of the presence of the heart within the chest. Wounds of the heart were known and their danger commented upon: "A severe wound of the bladder, brain, heart, midriff, one of the smaller intestines, belly or liver is deadly." Aphorisms VII, 18 (Jones, 1923-1931). One clinical reference indicates that the cardiac impulse was felt. This case report, possibly of delirium tremens, includes the comment that: "there was violent palpitation of the heart." Epidemics III, Case 16 (Jones, 1923-1931). In any case, the character and rate of the apex beat were not considered. Clubbing of the fingers was described in cases of empyema, but not in cases suggesting cyanotic heart disease: "All sufferers from empyema may be distinguished by the following symptoms ... the fingernails are bent and the fingers grow hot, especially at the tips." Prognostic XVII (Jones, 1923-1931). Cyanosis was noted in critically ill patients but again cannot be clearly related to heart disease: “. . . if the nails and fingers turn livid, death may be expected forthwith." Prognostic IX (Jones, 1923-1931). Vascular pulsation was mentioned by Hippocrates, for example: "throbbing of the veins" was included among the effects 
of undiluted wine on those accustomed to wine mixed with water, Regimen in Acute Diseases XXXVII (Jones, 1923-1931), and pulsation of the temporal arteries was noted: "in fevers, when the veins of the forehead are throbbing. ..." Coan Prognostics 125 (Littré, 1839-1861; Chadwick and Mann, 1950). The prognostic significance of changes in pulse rate were overlooked and probably not recognized by Greek physicians until the latter half of the fourth century B.C. (Albutt, 1921; Bedford, 1951).

Heart Failure. Hippocrates probably encountered cases of heart failure, although few clear examples can be found in the Hippocratic collection. The two symptoms suggesting heart failure most frequently noted were dropsy and dyspnœa. Dropsy was not, however, related to heart disease and dyspnca usually appears in cases recognizable as pneumonia or tuberculosis. An excellent description of what may be congestive failure with cardiac cirrhosis is found in one of the Cnidan books: "[the patient] appears yellow; the whole body is œdematous; the face is red; the mouth is dry; he is thirsty; and when he eats, respiration quickens. In the same day at some times he may appear better while at others he is suffering acutely and seems on the verge of dying." Internal Affections XXI (Littré, 1839-1861). Pitting œdema was distinguished from the indurated œdema of local inflamations: "Swellings that are painful, big and hard, indicate a danger of death in the near future; such as soft and painless, yielding to the pressure of the finger, are of a more chronic character." Prognostic VII (Jones, 1923-1932). The relation of dyspnœa to disorder of the heart was indicated in a book based on Hippocrates' work, but one that included much speculative physiology: "Should the discharge [i.e. phlegm coming from the brain] make its way to the heart, palpitation and difficulty of breathing supervene ... for when the phlegm descends cold to the lungs and heart, the blood is chilled; and the veins, being forcibly chilled, beat against the lungs and heart, and the heart palpitates, so that under this compulsion difficulty of breathing and orthopnœa result." The Sacred Disease IX (Jones, 1923-1931). An account of the diseases that give rise to anasarca appears in a book, possibly from the school of Cos, which may have been based on Hippocrates' teachings: "Dropsy is usually produced when a patient remains for a long time with impurities of the body following a long illness. The flesh is consumed and becomes water; this follows disease of the spleen [possibly malaria], of the liver, and leucophlegmasia [possibly acute nephritis] and dysentery and severe diarrhœa. As a result of the impurities, the abdomen fills with water; the feet and legs swell, the shoulders, clavicles, chest and thighs melt away. If you begin treatment at the beginning, before the accumulation of water becomes excessive, you must administer purgatives which evacuate water or phlegm ... the regimen of food, drink, exercise and walking will be until the patient becomes thin and dry, but only until the flesh becomes as strong as possible. This illness is fatal, above all through progression of ascites. [Regardless of cause] the treatment is similar; but few survive ... If the patient is relieved by the medication, and the rest of this regimen, the abdomen may be emptied as well; if not, one drains off the water by means of an incision; the incision used is either beside the umbilicus or behind at the flank." Affections XXII (Littré, 1839-1861). Further comment about paracentesis is found in a sophistic essay of the Hippocratic collection probably written during Hippocrates' lifetime: "Patients [suffering from dropsy] already at death's door are pumped dry of the water. Now the water appears to come copiously from the cavity at first, becoming less plentiful after a time. . . . When the cavity has been completely emptied, not even three days elapse before [it is] full again." Breaths XII (Jones, 1923-1931). The pathogenesis of the ascites was here stated to be disordered movement of air (pneuma). Directions for carrying out thoracentesis are found in one of the Cnidan works: "Incise over the third rib, down to the bone; then drill through the rib with a trephine. The perforation completed, remove a little water, and after the evacuation, put in a plug of raw flax, and over this, a soft sponge; you must then apply a bandage so that the plug does not fall out. You must take off the water over a period of twelve days, once daily; after the twelve days, on the thirteenth, evacuate all of the water. For the remaining time, if more water forms, you must remove it. ..." Internal Affections XXIII (Littré. 1839-1861). Hippocrates warned of the danger of too rapid drainage by thoracentesis or paracentesis: "Those cases of empyema or dropsy which are treated by incision or cautery, if the water 
or pus flow rapidly, all at once, prove fatal." Aphorisms VI 27 (Littré, 1839-1861; Jones, 19231931; Adams, 1849). At the conclusion of the passage describing thoracentesis, acupuncture was advised in cases where œdema arose as a complication: "If the genitals and thighs become œdematous, one must, without fear, scarify them." Internal Affections XXIII (Littré, 1839-1861). Venesection was recommended in the treatment of dropsy in several of the books of the Hippocratic collection, but the usual therapy was mild exercise and a dietary regimen. One example of the latter, which was not entirely unreasonable, was written as an aphorism: "Starving should be recommended for persons with moist flesh, for starving dries bodies." Aphorisms VII, 60 (Jones, 1923-1931). Another regimen for patients with anasarca is found in a work composed of fragments, possibly based on Hippocrates' work: "Those with dropsy must tire themselves, sweat, eat bread, drink little, and wash their heads with plenty of water, not hot but tepid; white wine and much sleep are to be avoided." Epidemics VII, LXVII, A (Littré, 1839-1861). Although Hippocrates was aware of the diuretic effect of strong wine, which: "passes readily into the bladder", Regimen in Acute Diseases LI, (Jones, 1923-1931), its use in dropsy was not mentioned. Considering these passages, it appears likely that heart failure was observed and treated by Hippocrates. However, it was not common and the signs of failure were often a complication of other diseases.

Two syndromes bearing the names of 19th century physicians were discribed by Hippocrates. The reference to Cheyne-Stokes respiration is frequently quoted: "Respiration rare and large with long intervals, becoming afterwards short." Epidemics III, Case 5. "The breathing throughout, as though he were recollecting to do it, was rare and large." Epidemics I, Case 1 (Jones, 1923-1931). Jones's comment on the meaning of the second passage is: "the patient seemed to forget the necessity of breathing and then to remember it and breathe consciously." (Jones, 1923-1931). Attacks resembling cardiac syncope were described in one of the aphorisms: "Those who suffer from frequent and strong faints without any manifest cause, die suddenly." Aphorisms II, 41 (Jones, 1923-1931; Chadwick and Mann, 1950). This appears to be Adams-Stokes syndrome although Hippocrates would not have noted the slow pulse if, indeed, he was referring to cases with complete heart block.

Rheumatic Fever. There are several references to a condition which was probably rheumatic fever. In the paragraph following a discussion of diseases of the throat, Hippocrates wrote: "If a fever be protracted, although the patient is in a state indicating recovery, and pain does not persist through inflammation or any other obvious cause, you may expect an abcession, with swelling and pain, to one of the joints, especially to the lower ones. Such abcessions come more often, and earlier, when patients are under thirty. You must expect the occurrence of an abcession if the fever lasts longer than twenty days; but in older patients, it is less likely even if the fever be more protracted. . . . You must know that in winter the abcessions are more likely to occur and are longer in coming to an end. . . ." Prognostic XXIV (Jones, 1923-1931). This condition could be metastatic infection, but other descriptions indicate the appearance of rheumatic nodules as well as arthritis: "in protracted fevers, tumours and pains at the joints come on." Aphorisms VII, 64 (Jones, 19231931). The author of another work in the Hippocratic collection, referred to previously, provides the most convincing description of acute rheumatic fever: "In arthritis, fever sets in, sharp pains seize the joints of the body; and these pains, often sharper, often milder, attack one joint, then another ... [This illness] is of short duration and severe, but not fatal; it affects the young more readily than old people." Affections XXX (Littré, 1839-1861). If rheumatic fever was prevalent in Greece at this time, one might expect to recognize rheumatic heart disease as it appears in young adults. Such a case is that of heart failure occurring in pregnancy: "Harpalida's sister, in the fourth or fifth month of her pregnancy, had watery swellings in her legs, swellings in the hollows of her eyes, and her whole body puffed up. . . . Besides these she had a dry cough, sometimes orthopnœa, dyspnœa and suffocation. Sometimes she was so near to suffocation that she was obliged to sit up in her bed without being able to lie down; and if she tried to sleep it was in a sitting position. Yet there was not much fever. For a long time the fœtus did not move, as if it were dead. . .." Epidemics VII VI (Littré, 1839-1861; Clifton, 1734). The case history continues with a description of the 
diet imposed and concludes with the comment that dyspnœa lasted for two months, resolving at the same time she was delivered of a child (We are not told if it was a live birth). These symptoms, occurring early in the second trimester of pregnancy, could well have been due to rheumatic heart disease.

Angina Pectoris. Perhaps the most interesting of the Hippocratic references to heart disease are those that suggest the diagnosis of angina pectoris and myocardial infarction. These are not numerous and were often included with discussions of pneumonia, empyema, and disease of the throat. Angina*, while frequently mentioned, is usually a symptom in cases likely to be streptococcal pharyngitis, tonsillitis, tetanus, and possibly diptheria. There is one description of chest pain with the character and radiation of cardiac pain; this appears in a discussion of the treatment of diseases of the chest: "Should, however, the pain show signs of extending to the collar bone or should there be a weight in the forearm, or in the region of the breast, or above the diaphragm, you must open the inner vein at the elbow. ..." Regimen in Acute Disease XXII (Jones, 1923-1931). This pain was distinguished from localized chest pain due to empyema which called for warm application at the site of the pain. The typical relation of cardiac pain to exertion was not mentioned by Hippocrates but the aggravation of angina pectoris by cold winds may be the subject of the following aphorism: "Of daily constitutions, such as are northerly ... aggravate any pre-existing pain in the chest. ..." Aphorisms III, 17 (Jones, 1923-1931). In a discussion of the causes of angina, Hippocrates may have been describing myocardial infarction when he wrote: "Angina is serious and rapidly fatal when no lesion is to be seen in either throat or neck, and moreover, it causes very great pain and orthopnoea; it may suffocate the patient even on the first day, or on the second, third or fourth." Prognostics XXIII (Jones, 1923-1931). Further evidence that angina pectoris was observed at the time of Hippocrates appears in Coan Prognostics, 280 where it is stated that: "Frequent attacks of pain in the chest of an old person often denote sudden death." (Littré, 1839-1861; Chadwick and Mann, 1950). Coronary disease was not, however, sufficiently common for Hippocrates to have included chest pain among the symptoms affecting old men: "Old men suffer from difficulty of breathing, catarrh accompanied by coughing, strangury, difficult micturition, pains at the joints, kidney disease, apoplexy, cachexia, pruritis of the whole body, sleeplessness, watery discharge from the bowels, eyes and nostrils, dullness of sight, cataract, hardness of hearing." Aphorisms III, 31 (Jones, 1923-1931).

Epidemiology. One of the first epidemiological studies of disease is found in the Hippocratic collection. This book, Airs, Waters, Places, was included among the genuine works of Hippocrates by all of the ancient and most modern commentators and translators. Jones (1923-1931) regarded it as very close to Hippocrates although it tended to "facile and unwarranted generalization." The central thesis of this work is the relation of climate to specific diseases. The most famous epidemiologic observation is the occurrence of malaria in people who live near stagnant water and marshes. From the point of view of cardiovascular diseases, the correlation between overweight and atherosclerosis may have been responsible for the following statements, made in a catalogue of the infections and constitutional diseases that occur in temperate and tropical climates: "A city that lies exposed to the hot winds ... Most of [the inhabitants] have a rather flabby physique.... When they are more than fifty years old they are paralysed by catarrhs supervening from the brain..." "But the following is the condition of cities with the opposite situation, facing cold winds. ... The natives must be sinewy and spare ... These men are more likely to be long-lived than are other." Airs, Waters, Places III, IV (Jones, 1923-1931). The conclusion in this work was that climate influenced both body habitus and longevity. A modern interpretation of the same observations would probably be that obesity predisposed to cerebrovascular disease and the slender person is likely to outlive his heavier neighbour. The latter proposition finds support from Hippo-

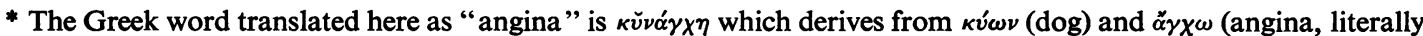
'squeeze'). Galen considered this word to mean an inflammation of the throat (Liddell and Scott, 1940) but it is clearly used to describe the choking symptom of tetanus (See for example, Internal Affections LIII (Littré, 1839-1861)) and possibly of cardiac pain as well. 
crates who condemns overeating: "repletion, carried to extremes, is perilous." Aphorisms I (Jones, 1923-1931). The danger of obesity was indicated: "Those who are constitutionally very fat are more apt to die quickly than those who are thin." Aphorisms I, 44 (Jones, 1923-1931). Especially is this so in older people: "Size of body in youth is noble and not unpleasing; in old age it is inconvenient and less desirable than a smaller stature." Aphorisms II, 54 (Jones, 1923-1931). It cannot be established that Hippocrates was concerned with vascular disease in making these observations but the statements are certainly in accord with the current understanding of the relation between overweight and atherosclerosis.

\section{CONCLUSION}

These references to the heart were recorded almost 2500 years ago at a time when knowledge of anatomy was fragmentary and a priori systems of physiology dominated scientific thought. Pathological physiology was consequently non-existent and the physician was unaware of the significance of most elements of the clinical examination. In spite of these handicaps, Hippocrates and his contemporaries recorded clinical descriptions recognizable as heart failure, Adams-Stokes syndrome, Cheyne-Stokes respiration, rheumatic fever, and cardiac pain.

The author would like to thank Dr. Olivier Polis for assistance in translating into English many of the passages quoted in this paper. The helpful comments of Dr. Richard Emanuel and Dr. Jane Somerville are also acknowledged.

\section{REFERENCES}

Adams, F. (1849). The Genuine Works of Hippocrates. The Sydenham Society, London.

Allbutt, T. C. (1921). Greek Medicine in Rome. Pp. 300 ff., Macmillan and Co., Ltd., London.

Bedford, D. E. (1951). Brit. Heart J., 13, 423.

Chadwick, J., and Mann, W. N. (1950). The Medical Work of Hippocrates. Blackwell Scientific Publications, Oxford.

Clifton, F. (1734). Hippocrates. J. Watts, London.

Edelstein, L. (1939). Bull. Hist. Med., 7, 236.

Hurlbutt, F. R. (1939). Bull. Hist. Med., 7, 1104.

Jones, W. H. S. (1923-1931). Hippocrates. Vol. I, II, and IV. William Heinemann, London.

Katz, A. M. (1959). Arch. intern Med., 104, 653.

Liddell, H. G., and Scott, R. (1940). A Greek-English Lexicon. The Clarendon Press, Oxford.

Littré, E. (1839-1861). Oeuvres Complètes d'Hippocrate, Vol. I-X. J. B. Baillière, Paris.

Withington, E. T. (1927). Hippocrates, Vol. III. William Heinemann, London. 